\title{
Deep Vein Thrombosis and Pulmonary Embolism: Two Complications of COVID-19 Pneumonia?
}

\author{
Erika Poggiali, Davide Bastoni, Eva loannilli, Andrea Vercelli, Andrea Magnacavallo \\ Emergency Department, Guglielmo da Saliceto Hospital, Piacenza, Italy
}

Received: 04/04/2020

Accepted: 06/04/2020

Published: 08/04/2020

How to cite this article: Poggiali E, Bastoni D, loannilli E, Vercelli A, Magnacavallo A. Deep vein thrombosis and pulmonary embolism: two complication of COVID-19 pneumonia? EJCRIM 2020;7: doi:10.12890/2020_001646.

Conflicts of Interests: The Authors declare that there are no competing interests.

Acknowledgements: The authors thank all emergency staff in their hospital for their hard work, strength and help in facing such a difficult public health crisis.

This article is licensed under a Commons Attribution Non-Commercial 4.0 License

\section{ABSTRACT}

Coronavirus disease 19 (COVID-19) is a worldwide infection which was recently declared a global health emergency by the WHO Emergency Committee. The most common symptoms are fever and cough, which can progress to pneumonia, acute respiratory distress syndrome (ARDS) and/or end-organ failure. Risk factors associated with ARDS and death are older age, comorbidities (e.g., hypertension, diabetes, hyperlipidaemia), neutrophilia, and organ and coagulation dysfunction. Disseminated intravascular coagulation and coagulopathy can contribute to death. Anticoagulant treatment is associated with decreased mortality in severe COVID-19 pneumonia. In this report we describe two patients with COVID-19 pneumonia who developed venous thromboembolism.

\section{LEARNING POINTS}

- Deep vein thrombosis and pulmonary embolism can occur in patients with COVID-19 pneumonia.

- Low-molecular-weight heparin prophylaxis does not decrease the risk of venous thromboembolism (VTE) in COVID-19 pneumonia.

- In the presence of clinical signs and/or suspicion of VTE, compression ultrasound and echocardiography should be always performed, irrespective of disease stage.

\section{KEYWORDS}

COVID-19 pneumonia, deep vein thrombosis, venous thromboembolism, pulmonary embolism, heparin

\section{INTRODUCTION}

Coronavirus disease 2019 (COVID-19) is a viral infection which has spread rapidly throughout the world and was declared a global health emergency by the WHO Emergency Committee in January 2020. Dry cough and fever are the most common symptoms of COVID-19 infection, which can progress to pneumonia, acute respiratory distress syndrome (ARDS) and end-organ failure ${ }^{[1]}$. Risk factors for ARDS and death are older age, comorbidities (hypertension, diabetes), neutrophilia, lymphocytopenia, elevated inflammatory indices (C-reactive protein, serum ferritin), and organ (AST, albumin, creatinine, urea, LDH) and coagulation dysfunction (PT and D-dimer). In addition, patients with underlying cardiovascular disease can have an adverse prognosis ${ }^{[2]}$. Diagnosis of COVID-19 encompasses a mixture of clinical suspicion and imaging techniques, including point-of care lung ultrasound (US) and a chest CT scan $^{[3]}$.

The pathogenesis of COVID-19 infection is not clearly understood. Inflammatory cytokine storms and viral evasion of cellular immune responses play a central role in disease progression and severity ${ }^{[4]}$. 
A combination of antiviral and anti-inflammatory treatments could be useful to avoid ARDS and multiple organ failure ${ }^{[5]}$. Coagulopathy and disseminated intravascular coagulation are common complications of severe COVID-19 pneumonia and the most common causes of death ${ }^{[6]}$. Recently, the sepsis-induced coagulopathy $(\mathrm{SIC})$ score has been proposed as a new score for patients with sepsis and coagulopathy ${ }^{[7]}$, and the administration of heparin (mainly low-molecular-weight heparin, LMWH) has been demonstrated to be associated with decreased mortality in patients with severe COVID-19 with SIC criteria or with markedly elevated D-dimer ${ }^{[8]}$. At the time of writing, there have been no previous reports of deep vein thrombosis (DVT) or pulmonary embolism (PE) in COVID-19 pneumonia. We describe two cases of venous thromboembolism (VTE) in patients with COVID-19 pneumonia.

\section{CASE DESCRIPTION}

Case 1

An 82-year-old woman was admitted to our emergency department (ED) for a 5-day history of fever and general malaise. The patient was on oral azithromycin and amoxicillin-clavulanate without any improvement. She was an ex-smoker and had a medical history of hypertension and chronic obstructive pulmonary disease. At admission she presented severe respiratory failure $\left(\mathrm{PaO}_{2} / \mathrm{FiO}_{2} 55 \mathrm{mmHg}\right.$, respiratory rate 26 breaths/min) with a need for high-flow oxygen therapy. A lung ultrasound (US) showed diffuse B lines with pleural thickening and small subpleural consolidations. A chest CT scan and nasopharyngeal swab confirmed the diagnosis of COVID-19 pneumonia. Laboratory findings, including the SIC score, are reported in Table 1. Antibiotics were discontinued, and darunavir/cobicistat, hydroxychloroquine and LMWH at a prophylactic dose were started.

On day 12 after admission, the patient complained of an ache in her right leg and a sensation of warmth. She denied chest pain and dyspnoea $\left(\mathrm{PaO}_{2} / \mathrm{FiO}_{2}>300 \mathrm{mmHg}\right.$ on nasal prong oxygen). Physical examination revealed oedema of the right leg and signs of dehydration. Compression ultrasound (CUS) of the right common femoral vein indicated venous thrombosis (Fig. 1). Lung US showed multiple bibasal consolidations (Fig. 2). Echocardiography documented normal ventricular function in the absence of indirect signs of PE. The inferior vena cava had completely collapsed, indicating hypovolemia. An electrocardiogram (ECG) revealed sinus tachycardia. Blood tests showed elevated D-dimer (24131 mg/dl), fibrinogen (674 mg/dl), serum ferritin (765 ng/ml) and troponin I (57 ng/ml) (Table 1). As creatinine clearance was $\leq 30 \mathrm{ml} / \mathrm{min}$, continuous intravenous infusion of unfractionated heparin was started with close monitoring of partial thromboplastin time (PTT). The patient underwent a CT scan of the chest that showed diffuse bilateral consolidations and a crazy-paving pattern (visual CT score 70\%) (Fig. 3). Based on this finding, we introduced systemic corticosteroids. The patient is still recovering at the time of writing. Her clinical condition is progressively improving with complete resolution of acute renal failure after infusion of crystalloid fluids (Table 1). She needs only low-flow oxygen therapy. The heparin infusion was switched after 3 days to standard-dose LMWH (enoxaparin).

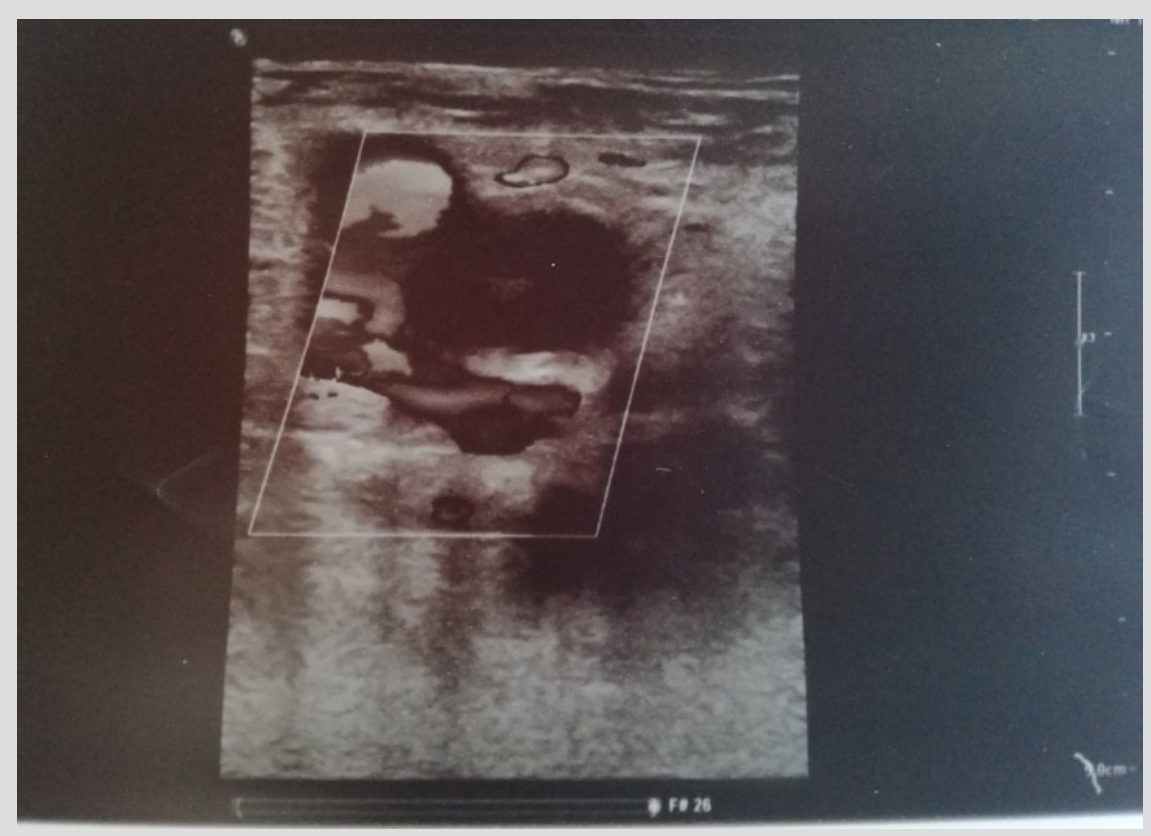

Figure 1. Compression ultrasound shows the incompressibility of the right common femoral vein 


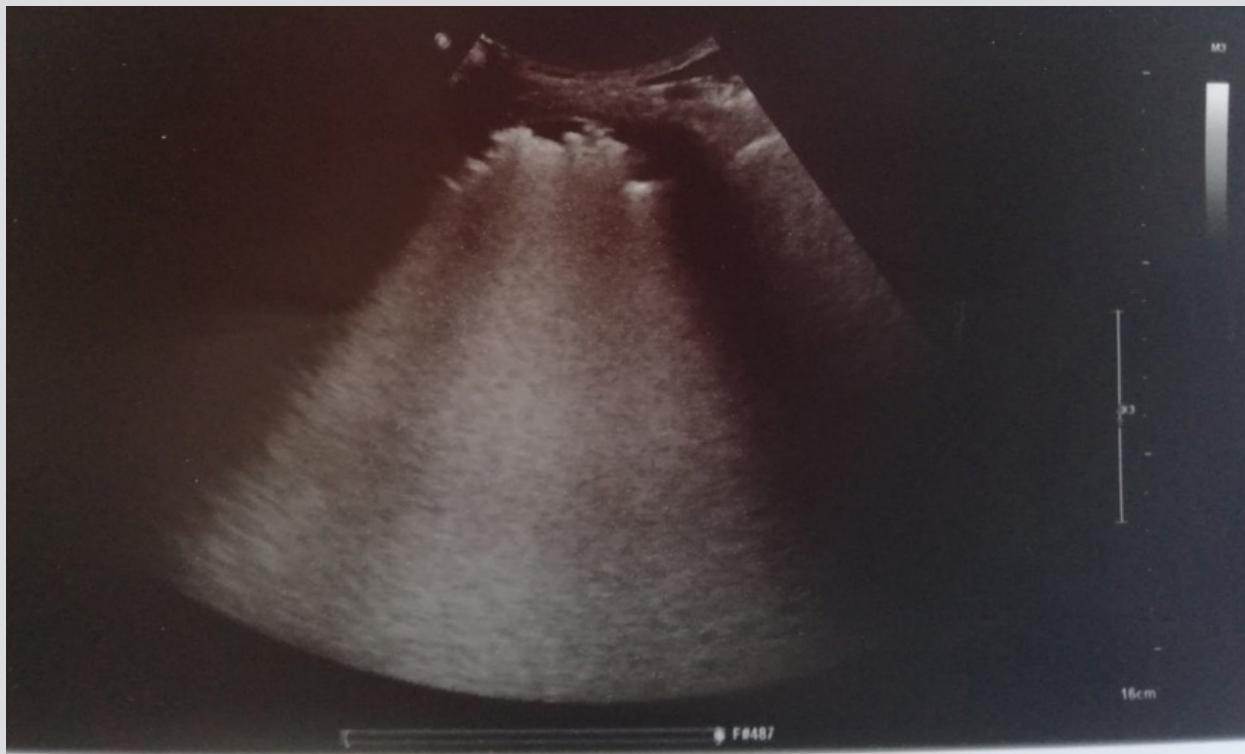

Figure 2. Point-of-care lung ultrasound. The image shows multiple basal consolidations

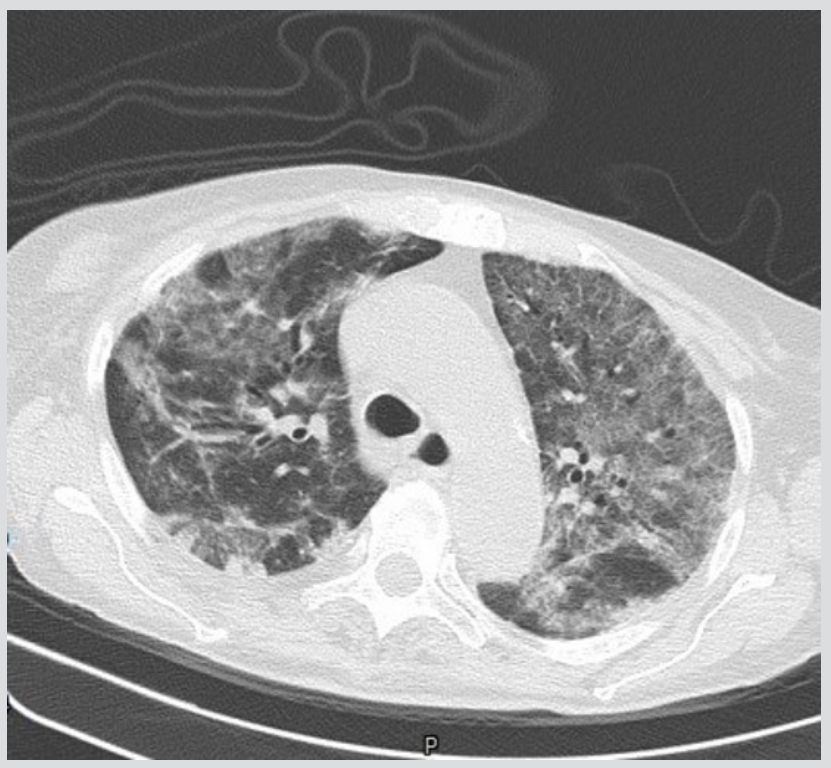

Figure 3. Lung CT scan. The image shows multiple ground-glass opacities and consolidations in both lungs

\section{Case 2}

A 64-year-old man was admitted to our ED complaining fever and dry cough treated with antibiotics over the previous 10 days. Pointof-care lung US revealed diffuse $B$ lines with bibasal consolidations which were also documented by chest $\mathrm{x}$-ray. A nasopharyngeal swab confirmed the diagnosis of COVID-19 pneumonia. Laboratory findings at diagnosis are reported in Table 2. The patient's medical history was unremarkable, and he did not take any medications. Right bundle branch block (RBB) was detected on ECG. He was treated with darunavir/cobicistat, hydroxychloroquine, LMWH at a prophylactic dose and low-flow nasal prong oxygen. He was discharged after 10 days in good health with no need for oxygen. His SIC score was below 4, so LMWH administration was stopped. However, after 1 week the patient again presented to our ED with complaints of acute chest pain while breathing $\left(\mathrm{SpO}_{2} 97 \%, \mathrm{PaO}_{2} / \mathrm{FiO}_{2} 341 \mathrm{mmHg}\right.$ on ambient air), and an ache in his left leg for the last 3 days. He denied previous venous thrombosis or a family history of thrombophilia. The clinically suspected DVT was confirmed by CUS with no compressibility of the left popliteal vein. Echocardiography was normal. Lung US showed focal B lines and left basal consolidation with slight pleural effusion (Fig. 4). ECG results were unchanged (NSR, RBBB). CT pulmonary angiography documented left subsegmental PE with diffuse ground-glass opacity and a crazy-paving pattern (visual CT score 5\%) (Fig. 5). 
Laboratory findings are reported in Table 2. Interestingly, the SIC score was normal ${ }^{[3]}$. Another nasopharyngeal swab was taken and showed low-positive results. Fondaparinux was immediately started at a high dose and switched to a twice daily regimen of dabigatran after 5 days. The patient was discharged without sequelae on day 6.

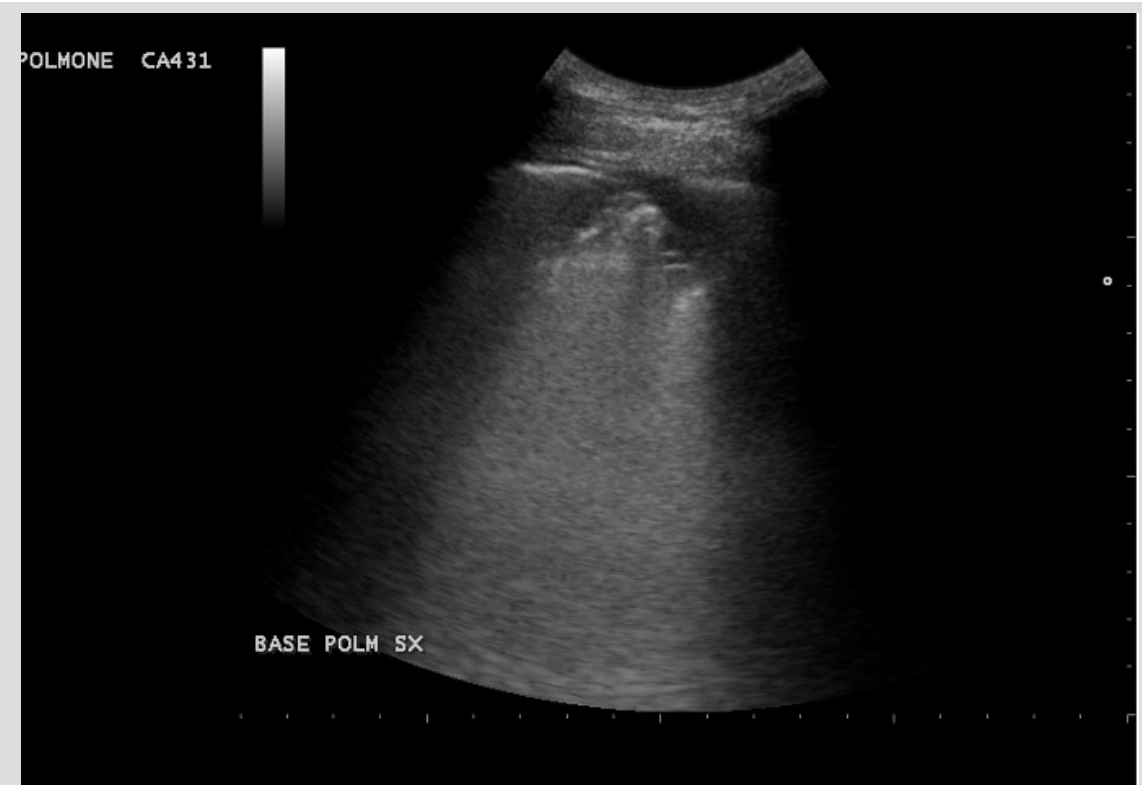

Figure 4. Point-of-care lung ultrasound. The image shows left basa consolidations with slight pleural effusion

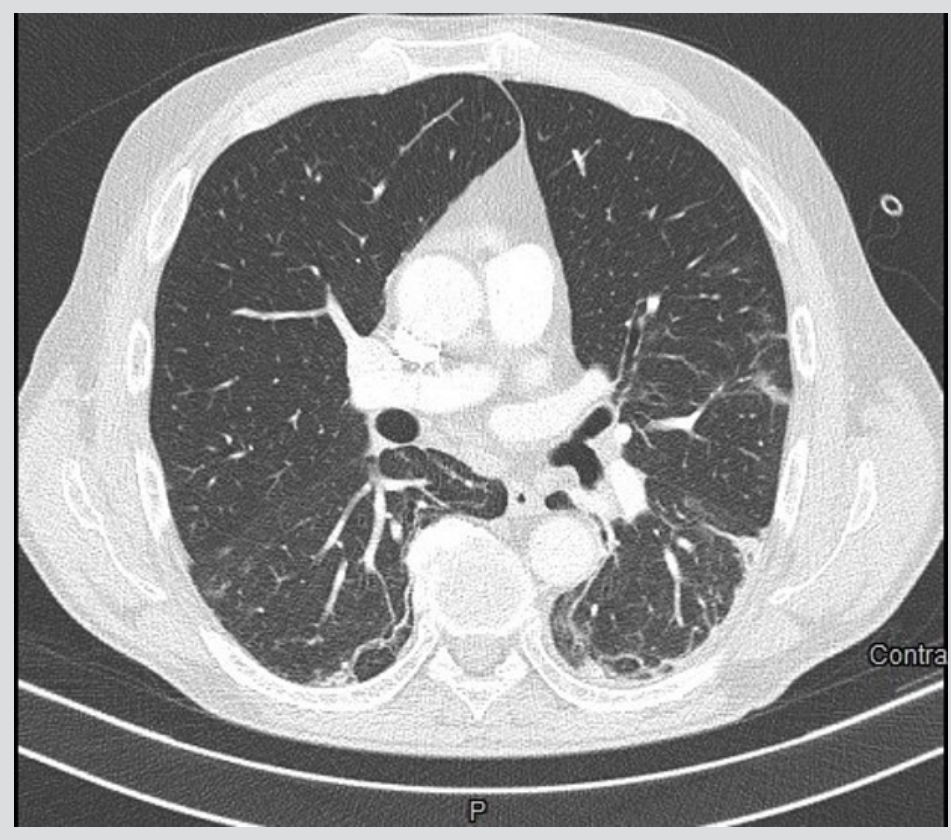

Figure 5. Left subsegmental pulmonary embolism on CT pulmonary angiography

\section{DISCUSSION}

VTE is a significant cause of morbidity and mortality. Risk factors include older age, immobilization, obesity, smoking and hospitalization. COVID-19 patients frequently complain of severe asthenia, fatigue and consequent inactivity, even at the beginning of the infection. In addition, risk factors for VTE include hypoxia and sepsis ${ }^{[9]}$, which are two common features of COVID-19. Anticoagulant treatment is associated with decreased mortality in severe COVID-19 pneumonia ${ }^{[8]}$, but no data have been reported in the literature for the different stages of COVID-19 infection. Furthermore, D-dimer is not a useful marker for diagnosing VTE in COVID-19, because it is generally increased, particularly in severe COVID-19 pneumonia, and is associated with the development of ARDS and progression from ARDS to death ${ }^{[1]}$. Based on all this evidence, if there are clinical signs and/or suspicion of VTE, CUS and echocardiography should always be 
performed, irrespective of disease stage. Our findings suggest that patients with COVID-19 pneumonia should be investigated for VTE even if treated with LMWH. [Q5]Both our patients seemed to be at risk of VTE even in the absence of hypoxaemia and severe respiratory failure, and it is clear VTE can increase the risk of death in COVID-19 patients.

Accurate knowledge of COVID-19 pathophysiology will be important in predicting and preventing VTE, and further studies are necessary to evaluate whether the SIC score can guide the decision to initiate anticoagulant therapy in COVID-19. Based on our experience, we believe that LMWH therapy at a prophylactic dose should be carefully considered in all patients with COVID-19 pneumonia for a longer period than required for clinical resolution of the disease.

\begin{tabular}{|c|c|c|c|}
\hline & At admission & Recovery day 12 & $\begin{array}{c}\text { Recovery day } 15 \\
\text { (day } 3 \text { of heparin infusion) }\end{array}$ \\
\hline WBC $\left(4-10 \times 10^{9} / I\right)$ & 10.26 & 13.06 & 12.28 \\
\hline Neutrophil count $\left(2-8 \times 10^{9} / I\right)$ & 6.56 & 9.73 & 9.25 \\
\hline 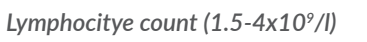 & 1.02 & 0.56 & 0.51 \\
\hline PLT count $\left(150-450 \times 10^{9} / 1\right)$ & 170 & 200 & 203 \\
\hline PT-INR & 170 & 200 & 203 \\
\hline PTT sec & 170 & 200 & 203 \\
\hline$C R P(<0.5 \mathrm{mg} / \mathrm{dl})$ & 20.4 & 13.81 & 11.98 \\
\hline PCT $(<0.5 \mathrm{ng} / \mathrm{ml})$ & ND & ND & 0.48 \\
\hline Fibrinogen $(150-400 \mathrm{mg} / \mathrm{dl})$ & ND & 674 & ND \\
\hline$D$-dimer $(<500 \mathrm{ng} / \mathrm{ml})$ & ND & 24131 & 7120 \\
\hline Troponin I (<31 ng/l) & ND & 57 & ND \\
\hline $\operatorname{LDH}(0-248 \mathrm{U} / \mathrm{I})$ & NA & 589 & 514 \\
\hline Serum ferritin $(150-400 \mathrm{ng} / \mathrm{ml})$ & ND & 765 & 1286 \\
\hline Creatinine $(0.6-1.2 \mathrm{mg} / \mathrm{dl})$ & 1.31 & 3.22 & 0.99 \\
\hline Blood urea nitrogen $(10-50 \mathrm{mg} / \mathrm{dl})$ & 93 & 264 & 95 \\
\hline Potassium (3.5-5.0 mEq/l) & 4.7 & 5.1 & 3.1 \\
\hline AST (10-37 U/I) & 56 & 43 & 61 \\
\hline ALT (10-37 U/I) & 21 & 15 & 28 \\
\hline Total bilirubin $(0.1-1.1 \mathrm{mg} / \mathrm{dl})$ & 1.3 & 1.31 & 1.25 \\
\hline $\mathrm{PaO}_{2} / \mathrm{FiO}_{2}(\mathrm{mmHg})$ & 55 (room air) & $>300$ (NC $6 \mathrm{l} / \mathrm{min})$ & $>350$ (NC $4 \mathrm{l} / \mathrm{min})$ \\
\hline SIC score ( $\geq 4)$ & 4 & 5 & ND \\
\hline
\end{tabular}

Table 1. Patient's laboratory findings at admission and during recovery

$A L T$, alanine transaminase; $A S T$, aspartate transaminase; $C R P, C$-reactive protein; $L D H$, lactate dehydrogenase; NC, nasal cannula; ND, not done; PCT, procalcitonin; PLT, platelet; PT, prothrombin time; PTT, partial thromboplastin time; SIC, sepsis-induced coagulopathy; WBC, white blood cell count. Abnormal values are in red. 
Internal Medicine

\begin{tabular}{|c|c|c|c|c|}
\hline & $\begin{array}{l}\text { At diagnosis of } \\
\text { COVID-19 } \\
\text { pneumonia }\end{array}$ & At discharge & $\begin{array}{c}\text { At re-admission to } \\
\text { ED }\end{array}$ & At discharge \\
\hline WBC $\left(4-10 \times 10^{9} / I\right)$ & 3.85 & 7.0 & 11.95 & 6.04 \\
\hline Neutrophil count $\left(2-8 \times 10^{9} / \mathrm{I}\right)$ & 2.49 & 5.49 & 9.99 & 4.4 \\
\hline Lymphocitye count $\left(1.5-4 \times 10^{9} / \mathrm{I}\right)$ & 1.02 & 0.93 & 1.07 & 0.93 \\
\hline PLT count $\left(150-450 \times 10^{9} / I\right)$ & 183 & 360 & 272 & 246 \\
\hline PT-INR & 1.51 & 1.49 & 1.34 & 1.42 \\
\hline PTT sec & 31.8 & 31.1 & 27.0 & 34.9 \\
\hline$C R P(<0.5 \mathrm{mg} / \mathrm{dl})$ & 10.57 & 0.71 & 11.52 & 7.93 \\
\hline PCT $(<0.5 \mathrm{ng} / \mathrm{ml})$ & 0.04 & 0.02 & ND & ND \\
\hline Fibrinogen $(150-400 \mathrm{mg} / \mathrm{dl})$ & 552 & ND & ND & 820 \\
\hline D-dimer (<500 ng/ml) & ND & ND & 1167 & 3440 \\
\hline LDH (0-248 U/I) & 291 & 227 & 201 & 204 \\
\hline Troponin I (<31 ng/l) & ND & ND & 3.6 & ND \\
\hline Creatinine $(0.6-1.2 \mathrm{mg} / \mathrm{dl})$ & 1.04 & 0.68 & 0.87 & 0.8 \\
\hline Blood urea nitrogen $(10-50 \mathrm{mg} / \mathrm{dl})$ & 35 & 35 & 30 & 42 \\
\hline Potassium (3.5-5.0 mEq/l) & 3.8 & 5.0 & 4.0 & 5.5 \\
\hline AST (10-37 U/I) & 38 & 29 & 18 & 21 \\
\hline $\operatorname{ALT}(10-37 \mathrm{U} / \mathrm{I})$ & 21 & 51 & 26 & 23 \\
\hline Total bilirubin $(0.1-1.1 \mathrm{mg} / \mathrm{dl})$ & 0.63 & 0.54 & 0.76 & 0.55 \\
\hline $\mathrm{PaO}_{2} / \mathrm{FiO}_{2}(\mathrm{mmHg})$ & 304 & 341 & 323 & 350 \\
\hline SIC score $(\geq 4)$ & 3 & 3 & 2 & ND \\
\hline
\end{tabular}

Table 2. Patient's laboratory findings at admission and during recovery

ALT, alanine transaminase; AST, aspartate transaminase; CRP, C-reactive protein; ED, emergency department; LDH, lactate dehydrogenase; ND, not done; PCT, procalcitonin; PLT, platelet; PT, prothrombin time; PTT, partial thromboplastin time; SIC, sepsis-induced coagulopathy; WBC, white blood cell count. Abnormal values are in red. 


\section{REFERENCES}

1. Huang C, Wang Y, Li X, Ren L, Zhao J, Hu Y, et al. Clinical features of patients infected with 2019 novel coronavirus 133 in Wuhan, China. Lancet 2020;395(10223):497-506.

2. Zheng YY, Ma YT, Zhang JY, Xie X. COVID-19 and the cardiovascular system. Nat Rev Cardiol 2020 Mar 5. doi: 10.1038/s41569-020-0360-5. [Epub ahead of print]

3. Poggiali E, Dacrema A, Bastoni D, Tinelli V, Demichele E, Mateo Ramos P, et al. Can lung ultrasound help critical care clinicians in the early diagnosis of novel coronavirus (COVID-19) pneumonia? Radiology 2020 Mar 13:200847. doi: 10.1148/radiol.2020200847. [Epub ahead of print]

4. Channappanavar R, Perlman S. Pathogenic human coronavirus infections: causes and consequences of cytokine storm and immunopathology. Semin Immunopathol 2017;39(5):529-539.

5. Stebbing J, Phelan A, Griffin I, Tucker C, Oechsle O, Smith D, et al. COVID-19: combining antiviral and anti-inflammatory treatments. Lancet Infect Dis 2020;20(4):400-402.

6. Wu C, Chen X, Cai Y, Xia J, Zhou X, Xu S, et al. Risk factors associated with acute respiratory distress syndrome and death in patients with coronavirus disease 2019 pneumonia in Wuhan, China. JAMA Intern Med 2020 Mar 13. doi: 10.1001/jamainternmed.2020.0994. [Epub ahead of print]

7. Iba T, Nisio MD, Levy JH, Kitamura N, Thachil J. New criteria for sepsis-induced coagulopathy (SIC) following the revised sepsis definition: a retrospective analysis of a nationwide survey. BMJ Open 2017;7(9):e017046.

8. Tang N, Bai H, Chen X, Gong J, Li D, Sun Z. Anticoagulant treatment is associated with decreased mortality in severe coronavirus disease 2019 patients with coagulopathy. J Thromb Haemost 2020 Mar 27. doi: 10.1111/jth.14817. [Epub ahead of print]

9. Mackman N. Mouse models, risk factors, and treatments of venous thrombosis. Arterioscler Thromb Vasc Biol 2012;32:554-555. 